\title{
The Role of the Radiographer on the Use of Informed Consent
}

\author{
Kyei K. A., Antwi W. K., Opoku S. Y., Yarney J., Amoah E. \\ University of Ghana, School of Biomedical and Allied Health Sciences, Korle-Bu, Accra, Ghana
}

Email address:

adesco41@hotmail.com (K. A. Kyei), kakyei@chs.ug.edu.gh (K. A. Kyei)

\section{To cite this article:}

Kyei K. A., Antwi W. K., Opoku S. Y., Yarney J., Amoah E.. The Role of Radiographer on the Use of Informed Consent. Clinical Medicine Research. Special Issue: Radiographic Practice Situation in a developing Country. Vol. 4, No. 3-1, 2015, pp. 10-13. doi: 10.11648/j.cmr.s.2015040301.13

\begin{abstract}
Background: Multidisciplinary health-care procedures do encounter some challenges that have some legal implications. One way of addressing these issues is by issuance and signing of medical consent. Obtaining medical consent is simply making sure that patients understand why a procedure is being recommended, which alternatives are available, what will happen if the procedure is not performed, how it will be done, and the risks involved. Aim: To assess information given to cancer patients before consent forms are signed and radiographers' role on its usage. Methodology: Qualitative approach was used to assess patients' information before signing consent and radiographers' role of it. Open and close questions were used. Data was analyzed using SPSS (Statistical Package for the Social Sciences) version 18.0. Forty participants were used for the study. Results: The study indicated all the patients were adequately informed before signing consent forms. $86.7 \%$ of the radiographers were aware of the role extension and its legal implications but are not aware of any establishment practicing role extension in Ghana. Conclusion: It was revealed that all the patients who participated were informed of their diagnosis, treatment options, the duration of treatment and the risks involved before taken their treatment decision. Almost all radiotherapists were aware of role extension but were not aware of any establishment seeking to practice it in Ghana.
\end{abstract}

Keywords: Radiographer, Informed Consent, Role, Practice

\section{Introduction}

Modern multidisciplinary cancer care involves a lot of legal issues such as medical consent. Medical consent is a form of consent which must be obtained before performing medical procedure (Smith, 2003). Informing patients involves making sure that a patient understands why a procedure is being recommended, which alternatives are available, what will happen if the procedure is not performed, how the procedure will be done, and what the risks and benefits of the procedure are [1]. Informed consent is not simply a question of obtaining a signature form from a patient; it is a voluntary agreement of a mentally capacitated person, base on necessary information to what is being proposed and preceded by a clear explanation to the patient. The person talking to the patients must be able to answer patient's questions fully and honestly and know the limit of their competent and when they need to bring in someone else to talk to the patient [2].

An informed consent can be said to have been given based upon a clear appreciation and understanding of the facts, implications and future consequences of an action. Before an individual gives an informed consent, he or she must have adequate reasoning faculties and be in possession of all relevant facts at the time consent is given. In case of any eventuality, the clinician is protected by law if the information given by the patient during consent signing is documented [3].The form should name the patient, the investigation, treatment or operation and the physician who is to carry out the treatment. There should be included an acknowledgement by the patient that explanations have been given about the nature of the treatment and its anticipated effect, and about any material risks and special or unusual risks.

The inform consent should address patient's acknowledgement that alternative forms of treatment or investigation have been discussed [3]. In the field of medicine, minors may give consent for their own medical treatment in several situations: as child who is legally considered adult and when the conditions they present 
covered by minor treatment status. Minors are more likely to seek health care when they are assured of confidentiality. Confidentiality is breached only when it is determined that there is a threat to the life of the minor [4]. A doctor or hospital may not legally treat a minor child without consent of a parent or legal guardian. For this reason, the law in many jurisdictions allows the parent or legal guardian to give temporary authority for another adult to consent to medical treatment in his or her absence through the use of a child medical consent document [5].

The Department of Health, [6], highlighted on the need for quality care centered on the patient and for changes in the way patients are asked to give consent to treatment. This is in accordance with the policy framework that seeks the ultimate responsibility of the health professional to ensuring that the patient consent to the procedure to what is being done.

In radiotherapy, the radiation oncologist who obtains consent as they are responsible for prescribing doses of treatment but the Radiographer's role is to deliver treatment as prescribed [7].

The bottom line is the explanation given by the physician and the dialogue between him and the patient about the proposed treatment is the important element of the consent process. The consent form itself is not the "consent." It is simply evidentiary, written confirmation that the explanations were given and that the patient agreed to what was proposed [6].

Most research on informed consent focuses on ethics and is currently limited to individual institutions or some nongovernmental organizations [8].

There is widespread adherence to guidance for obtaining consent and a growing number of centres are implementing Radiographer-led consent. However, this is controversial from both medical and radiographic professional perspectives despite guidance indicating that the person who is actually treating the patients should seek their consent [6]. The issue there is; patients get enough information before they sign their treatment consent forms; do radiographers have a part to play on the use of informed consent. The aim of the study is to find out whether information given to cancer patients prior to cancer treatment is adequate.

\section{Methodology}

A qualitative research method with a random probability sampling method was used and the study was conducted with fifteen Radiographers and twenty-five cancer patients who were going through their routing treatment. A random sampling method was used in selecting a sample size of forty for the study. This included 25 patients representing a fraction of $5 / 8$ of patients who were going through their daily treatment within the period of the study and 15 radiographers representing a fraction of $15 / 17$. In total, a fraction of $40 / 57$ was used due to time constrain.

Selected radiographers were approach to complete a structured questionnaire. Enough time was given to respondents to answer the questionnaires free from coercing, in situations where respondents did not understand, vivid explanations were given. Those who could not read or write were assisted directly by the researcher to complete their forms. The data was analyzed using SPSS version 17.0 whiles' frequency tables and graphs were plotted from the data, pie and bar charts were also used.

Approval for the study was obtained from the research ethics committee of a higher education institution. The ethics approval was supported by written permission for the study to be conducted at the study site. All study participants gave informed consent prior to the commencement of the study.

\section{Results}

The analysis included 40 respondents made of 22 males (45\%) and 22 females (45\%). Most of the patients' respondents are of age 51+. Majority of radiographer respondents were single (12) whereas most of patient respondents were mostly married. Most of the patients were self-employed where as the radiographer respondents were public servants. All radiographer respondents were of tertiary education whiles most of the patients were within the primary education level. All the patients indicated that they were informed about diagnosis and the kind of treatment to receive. All the patients were of the view that treatment was explained to them.

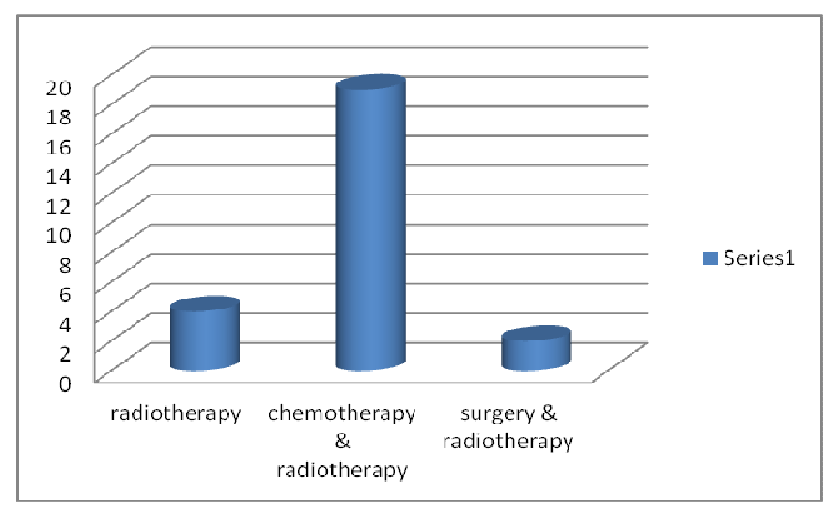

Figure 1. Patients' to the treatment modality

It can be noticed that most patients had both chemotherapy and radiotherapy.

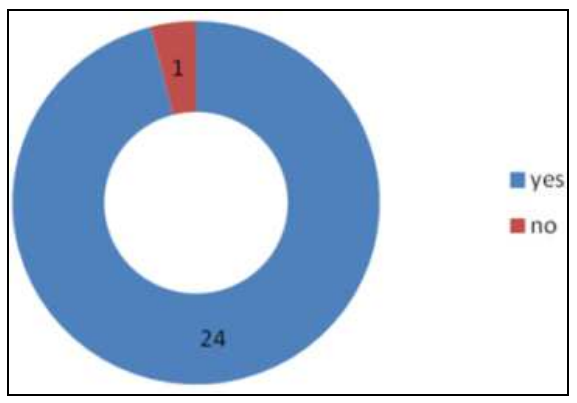

Figure 2. Explanation of treatment side effects

Patients were of the view that the medical providers used simple language for the explanation of treatment modality. 
Results also show that all the patients understood the explanation of the treatment modality explained to them as it was noticed that, the duration of the entire treatment was made known them, this recorded $100 \%$. From the results, no patient was coerced or forced to sign the consent form as all of them indicated that.

$96 \%$ of respondents opted "yes" indicating that treatment side effects were explained to them.

Table 1. Advice given to patients on side effects

\begin{tabular}{llll}
\hline & Frequency & Percent & Cumulative Percent \\
\hline Yes & 23 & 92.0 & 92.0 \\
No & 2 & 8.0 & 100.0 \\
Total & 25 & 100.0 & \\
\hline
\end{tabular}

Greater portion $(92 \%)$ of the patients was told of what to do if the side effect arises.

Table 2. Issuance of consent form to patients

\begin{tabular}{llll}
\hline & Frequency & Percent & Cumulative Percent \\
\hline Yes & 24 & 96.0 & 96.0 \\
No & 1 & 4.0 & 100.0 \\
Total & 25 & 100.0 & \\
\hline
\end{tabular}

$96 \%$ of patients stated that consent form was given to them.

Table 3. Whether patients were made to take their own decision or not

\begin{tabular}{llll}
\hline & Frequency & Percent & Cumulative Percent \\
\hline Yes & 25 & 100.0 & 100.0 \\
No & 0 & 0.0 & 0.0 \\
Total & 25 & 100.0 & \\
\hline
\end{tabular}

The table shows that all the patients were allowed to make their own treatment decision.

Table 4. Establishments seeking to advance role extension in Ghana

\begin{tabular}{llll}
\hline & Frequency & Percent & Cumulative Percent \\
\hline Yes & 1 & 6.7 & 6.7 \\
No & 5 & 33.3 & 40.0 \\
not aware & 9 & 60.0 & 100.0 \\
Total & 15 & 100.0 & \\
\hline
\end{tabular}

Most radiographers are not aware of "any establishment seeking to advance role extension in your department". This recorded $60 \%$ of radiographer respondent followed by a "No" of $33.3 \%$ of total responses with "Yes" taking the least.

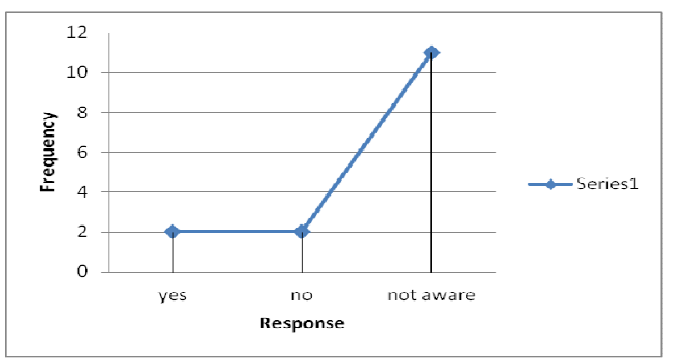

Figure 3. Developmental programmes for radiographers who want to take up extension on patients' informed consent

It was realized that most of radiographers are not aware of any developmental programmes for radiographers who want to take up such role in patient informed consent.

Table 5. Legal implications on administering informed consent?

\begin{tabular}{llll}
\hline & Frequency & Percent & Cumulative Percent \\
\hline Yes & 15 & 100.0 & 100.0 \\
No & 0 & 0.0 & 0.0 \\
Total & 40 & 100.0 & \\
\hline
\end{tabular}

All radiotherapists were aware of the legal implications on administering informed consent.

\section{Discussion}

Majority of the radiographers were of ages between 18 and 28 years whereas majority of the patients were above the age 51.Most of the patients respondents were female $(68 \%)$ and majority of the radiographers' respondents were male (66.7\%). Sankar et al, [9] found out that educational level was an important factor in having sufficient knowledge about every treatment. It was found out that all the radiographers' had attained some level of tertiary education. In the case of patients, majority had primary education, however, patients who had tertiary education, appreciated the treatment modality and its side effects. This may be attributed to the fact that they interact with their clinicians and have the capacity to making decision for themselves. It is also suspected that they demanded a lot of information from their clinicians and this supports the study of [10].

\subsection{Patients' Response}

All the patients $25(100 \%)$ were informed of their diagnosis and the treatment modality explained to them. It shows that the clinicians used very simple language in explaining the treatment modalities to the patients. All the patients indicated that they were not coerced to sign the consent form. It was realized that explanation given to patients concerning treatment procedures were clear and they understood it. The duration of the entire treatment was also explained to the patients, as all of them responded yes to the question posed.

Informed consent has been the disclosure of risks to the patient in regard to the procedure at hand and this act of disclosure should actually be about putting the patient in a position to make an autonomous decision [11]. From figure 1, almost all the patients were well-informed about the side effects of the treatment. This is an indication that the clinicians took their time to explain the effects of the treatment in simplest terms. Some patients seem to forget about things easily due to the stage at which their sickness has gotten into; such patients could easily opt for "no" as an answer. This confirms [11] that patients do not necessarily remember what physicians tell them before operation as to the topics of morbidity, mortality, and pain. They also, sometimes, do not acquire, process, or retain the information related to risks presented to them preoperatively. This "depletes" the morality of informed consent before treatment.

From table 4 greater portions of the patients were told of 
what to do if the side effect arises and this is an indication that patients were given the platform to ask question about their diagnosis, the kind of treatment, risks involved and what to do when such risks are experienced during and after treatment. It also clearly shows that there was a better doctorpatient relationship. Signing the consent form which is the last element of informed consent [12], is where patient finally agrees and accepts the consequences and responsibilities of the treatment. The decision is morally and ethically informed if the patient is competent and does not lack the capacity to act, when disclosure occurs before consenting [13]. Table 4 gave clear indication that almost all the patients were given consent form before treatment to sign or thumb print. The study also showed no patient was forced or coerced to sign the consent form.

\subsection{Radiographers' Role}

Most of the radiographers were not aware of any establishment seeking to advance role extension. Could it be the cost involve in training the staff, [14] indicated.

Although most of the radiotherapists were unaware of any establishment ready to undertake role extension, they all seemed to be aware of the legal implications involved and are all well-prepared to deals with them. From figure 5 radiographers were aware of the legal implications on administering informed consent, whilst $80 \%$ of them were prepared to deal with the legal issues.

\section{Conclusion}

The study was to find out whether the information given to patients before consent signing prior to their treatment schedules was adequate and the role of radiographers on the use of informed consent. It was revealed that all the patients who participated were informed of their diagnosis. They were adequately informed of the treatment options, the duration of treatment and the risks involved before taken their treatment decision. It is important; patients do not wait so long at the outpatient department before they are called for treatment as was revealed during data collection.

The study also revealed that the topic of role expansion for therapy radiographers has been thoroughly investigated in clinical settings worldwide. Multi-disciplinary healthcare has seen a gradual breakdown of role boundaries and an acceptance by most professionals that provision of a high quality service is dependent on a team approach [14]. This requires additional knowledge and skills as well as increased autonomy. Though the radiotherapists were aware of such expertise roles and were prepared to deal with the legal implications, no establishment was seeking to advance the course of role extension in Ghana.

\section{Recommendation}

Though the study showed patients were well-informed about their treatment and seemed to know what to do with its side effects, effort must be made by the radiotherapist to ensure that those who seem to forget things easily due to their conditions are reminded of the possible side effects and what to do as and when they manifest. Effort must be made to reduce patients' waiting time, appropriate appointment time should be given to patients and radiotherapists should also ensure that patients stick to their time.

\section{References}

[1] Smith M. Kathleen D. Jayne H. Legal issues related to dismissing students for clinical deficiencies: Nurse Educator, 2001; 26(1): 33-38.

[2] Diamond B. The legal aspect of complementary Therapy Practice. 2002; Churchill Livingston, Edinburg.

[3] Kenneth, G. Consent. A guide for Canadian Physician. 2006, $4^{\text {th }}$ edition.

[4] Barren J. Ethical dilemma in the care of minors in the emergencies department. Emergency medical clinic North America, 2006; 24 (3): 619-631.

[5] Renee MS, Virginia AJ. Pediatric Drug Development; the International Conference of Harmonization Focus on Clinical Investigation in Children. Drug Information Journal, 2000; 34 (3) $809-819$.

[6] Department of Health. Reference guide to consent for examination or treatment. 2001 www.dh.gov.uk/publications.

[7] Guillian T. Consent and information giving in radiotherapy. Journal of Radiotherapy in Practice, 2007; 6: 217-223.

[8] Bhuguri H, Qidwai W. Awareness of the process of informed consent among family practice patients in Karachi. J Park Med Assoc, 2004; 54:398-401.

[9] Sankar P, Mora S, Merz JF, Jones NL. Patients perspective of medical confidentiality; review of literature. Journal General Internal Medicine, 2003; 18: (659-691)

[10] Marklin, R. Ethics, informed consent, and assisted reproduction. J Assist Reprod Genet, 1995; 153(9): 1261-1268.

[11] Beauchamp TI, Childress JF. Principles of Biomedical Ethics. 1994; Oxford University Press.

[12] Beauchamp TL. Childress JF. Respect for Autonomy. In Principles of Biomedical Ethics (5th ed.). 2001, New York: Oxford University Press

[13] Aveyard H. Implied consent prior to nursing care procedures: Journal of advance Nursin,.2002; 39(2): 201-207.

[14] Colyer H. Radiography: An international journal of diagnostic imaging and radiation therapy, 2007; 13 (3): 197-201. 